\title{
Is Bitcoin Similar to Gold? An Integrated Overview of Empirical Findings
}

\author{
Nikolaos A. Kyriazis \\ Department of Economics, University of Thessaly, 38333 Volos, Greece; knikolaos@uth.gr
}

Received: 16 March 2020; Accepted: 27 April 2020; Published: 1 May 2020

check for updates

\begin{abstract}
This paper sets out to explore whether Bitcoin can be considered as a globally accepted asset that has a resemblance to gold, which is widely considered to be the safest choice. An integrated overview of the empirical findings generated by the nascent but increasingly proliferating literature concerning the nexus between Bitcoin and gold is provided. The majority of evidence reveals that Bitcoin has a long way to go before it acquires the same characteristics as the safe-haven asset of gold. Overall, Bitcoin is found to be an efficient hedge against oil and stock market indices, but to a lesser extent than gold. Bitcoin presents low or negative correlations or an asymmetric non-linear linkage with gold. Despite sharing some common features with traditional assets, Bitcoin is found to be a good hedging asset in portfolios with gold. Moreover, evidence reveals that gold is a better and more stable safe-haven investment than Bitcoin.
\end{abstract}

Keywords: Bitcoin; gold; cryptocurrency; survey; nexus

\section{Introduction}

Digital currencies have been innovative forms of liquidity that have caused increasing concern among investors and central authorities and heated debates among academics. Digital currency is a form of currency that is available in digital or electronic form while not in physical form. To be more precise, such currencies are digital goods with the three functions of money (means of transactions, store of value and unit of account) and are introduced by companies (Gans and Halaburda 2015). Related to that, but not identical, is the concept of cryptocurrency. A cryptocurrency is defined as a digital or virtual currency secured by cryptography, which is far from vulnerable to counterfeit or double-spending. Moreover, it is not dependent on national borders, monetary authorities, sovereigns, or fiats (Maese et al. 2016). Bitcoin was the first cryptocurrency launched and has emerged as the principal candidate for replacing legal central bank money and providing a useful alternative in liquid forms.

Recent research has emphasized whether or not Bitcoin can serve as money (Ammous 2018), and whether it could be better characterized as a commodity (similar to gold) or as a fiat money similar to the dollar (Selgin 2015; Dyhrberg 2016a, 2016b; Baur et al. 2018). Moreover, studies about the liquidity and tradability of cryptocurrencies (Wei 2018; Kyriazis and Prassa 2019) and efficiency characteristics (Fischer et al. 2019) have been conducted. Emphasis has also been put on academic research about the volatility of digital currencies (Beneki et al. 2019; Kyriazis et al. 2019; Fassas et al. 2020). It should be noted that integrated surveys on cryptocurrency characteristics have also taken place (Corbet et al. 2019; Kyriazis 2019a, 2019b; Fang et al. 2020) in a similar mentality to that of Papadamou et al. $(2019,2020)$. Nevertheless, the demystification of the complex character of digital currencies remains difficult.

The exploration of the nexus among assets of primary importance has been of great interest and lies at the center of the research agenda in recent academic studies about cryptocurrencies. Revealing the nexus among digital currencies and traditional assets is the key to accurately estimating the potential risks and benefits and diversifying or hedging capabilities of virtual forms of liquidity. This study 
aims to extend earlier research by providing an integrated overview of academic findings examining the linkages of digital currencies with gold, which is the most outstanding value-preserving asset.

Gold constitutes one of the most malleable, dense, conductive, non-destructive, brilliant, and beautiful of metals $\left(\mathrm{O}^{\prime}\right.$ Connor et al. 2015). These unique features render its intrinsic value almost impossible to alter as time passes and has enabled it to be accepted worldwide as the most representative hedge or safe haven against volatility in alternative assets. According to Baur and Lucey (2010), hedges are financial assets with no correlation or negative correlation with alternative assets. Additionally, when assets act as hedges during extreme economic conditions, they are considered to be safe havens.

In contrast, Bitcoin is a highly decentralized digital currency that carries an almost non-existent intrinsic value. It is considered to be a highly speculative means of investment and an extremely innovative form of payment. Bitcoin is an online communication protocol that enables the use of a virtual currency, including for electronic payments. Digital currencies exhibit some special characteristics that have rendered them highly popular, such as their pseudonymous character, low costs, and high speed in transactions that have led to serious discussions about digitalization of the financial system (Böhme et al. 2015).

This paper adds to existing research by providing a bird's-eye view on the existing linkages between the highly traditional asset of gold, which is especially popular during crises, with Bitcoin, which constitutes the most popular investment used for speculation, mainly during booming periods but also under more normal economic conditions. An integrated overview is laid out of empirical findings of the twenty-two academic studies concerning the intriguing nexus between Bitcoin and gold. The motivation of this paper is to provide a roadmap so as to better understand whether Bitcoin could act as a global asset like gold that would serve as a unit of measurement, a means for conducting transactions, or a preserver of value just as gold has successfully done over many centuries. Answers about this hot topic will cast light on the future of the financial sector and economies in a national but also a worldwide level and could form the basis of an outstanding spur in relevant academic research.

The remainder of this study is structured as follows. Section 2 presents relevant academic work that provides evidence of significant similarities between Bitcoin and gold. Section 3 lays out the studies that led to mixed results or found a weak or neutral linkage between the two assets. Section 4 analyzes the papers that reveal a very weak or negative connection between Bitcoin and gold and suggest that Bitcoin is far from being characterized as a safe haven similar to gold. Section 5 provides the economic underpinnings of this research, conducts an analysis of the outcomes, and provides a conclusion. Table A1 presents the basic features of all twenty-two studies under scrutiny. Figures A1-A9 provide statistics about citations and special features of the papers investigated.

\section{Studies Revealing a High Resemblance between Bitcoin and Gold Assets}

Current relevant literature breaks down into studies that investigate the linkage between Bitcoin and gold and lead to different conclusions about the nexus of Bitcoin and gold. The first strand purports to confirm the existence of strong similarities concerning hedging and safe-haven properties and capacities of acting as a medium of exchange, store of value and a unit of account. Academic papers by Dyhrberg (2016b); Selmi et al. (2018); Shahzad et al. (2019b) and Bouoiyour et al. (2019) display significant evidence of common features between these two highly popular but seemingly different assets. More specifically, Dyhrberg (2016a) employs Generalized Autoregressive Conditional Heteroskedasticity (GARCH) methodologies in order to conduct estimations. Intriguingly, specifications focusing on quantile estimations are employed by Selmi et al. (2018) and Shahzad et al. (2019b). Panagiotidis et al. (2018) employ Least Absolute Shrinkage and Selection Operator (LASSO) methodologies for the purpose of their estimations. Somewhat surprisingly, Markov-switching copulas and alternative risk regimes are adopted by Bouoiyour et al. (2019). 
To be more precise, Dyhrberg (2016b) provides similar findings about the nexus of Bitcoin with gold. The asymmetric power ARCH is adopted in this study and the time period spanned is the same as in Dyhrberg (2016a). Evidence reveals that Bitcoin constitutes an efficient hedger against traditional investment choices, such as the Financial Times Stock Exchange Group (FTSE) index. Furthermore, it can be employed as a hedger against the US dollar in the short-term. Conclusions support the notion that Bitcoin is useful for hedging purposes in portfolios and leads to overall lower risk. This gives credence to those who support that Bitcoin presents significantly similar features with gold.

By their own perspective, Selmi et al. (2018) employ a quantile-on-quantile regression specification in order to address the question of whether Bitcoin or gold can act as a better diversifier, hedger or safe haven against fluctuations in oil prices. The period examined covers from 13 September 2011 to 29 August 2017. Empirical results document that both Bitcoin and gold exhibit relevant hedging abilities against fluctuations in oil market values. Nevertheless, these capabilities vary across time according to whether Bitcoin or gold markets are flourishing or stressed. The same counts for oil markets. It is concluded that Bitcoin and gold constitute safe investment decisions during turbulent eras. Similar findings are extracted by the conditional value-at-risk methodology. When it comes to Shahzad et al. (2019b), they look into whether the safe-haven properties of Bitcoin are stronger compared to those of gold, stock markets and commodities in general. It should be noted that-based on a cross-quantilogram approach-a new definition about weak and strong safe-haven characteristics is provided. The period investigated spans from 19 July 2010 up to 22 February 2018. Based on econometric outcomes, it can be seen that both Bitcoin and gold constitute weak safe havens regarding the world stock market index, while gold is the only safe haven as concerns developed stock markets and carries the same ability in emerging stock markets. On the other hand, Bitcoin forms a weak safe-haven asset against Chinese stock indices. These findings are confirmed by rolling-window methodologies. Furthermore, evidence reveals that the safe-haven capacities of Bitcoin and gold are not stable over time or across alternative stock market indices.

Panagiotidis et al. (2018), by employing a Least Absolute Shrinkage and Selection Operator (LASSO) methodology, argue that Bitcoin is positively and strongly affected by gold. Moreover, the findings reveal that oil, exchange rates and interest rates trigger positive impacts on Bitcoin. On the contrary, it is supported that uncertainty reduces Bitcoin returns. Furthermore, information demands leads to the expected outcomes while stock markets provide mixed results. In another vein, Bouoiyour et al. (2019) employ a dynamic Markov-switching copula methodology and two risk scenarios for the purposes of testing the complementarity or substitutability between Bitcoin and gold. The scenarios cover low-risk and high-risk regimes. The period investigated starts from 18 July 2010 and ends at 31 March 2018. Econometric outcomes reveal that a positive and powerful correlation between Bitcoin and gold returns is present so these are likely to be complementary. It is found that gold exhibits diversifying benefits for investors in digital assets but Bitcoin is more capable of efficiently transferring value.

\section{Studies Providing Evidence of Mixed Results, Weak or Neutral Nexus between Bitcoin and Gold}

In order to elaborate on the arguments put forward by authors that have been led to findings about mixed, weak or very weak results, we dwell on the academic papers of Dyhrberg (2016a); Wu et al. (2019); Kang et al. (2019) and Gajardo et al. (2018). It should be emphasized that academic work revealing such impacts is totally dependent on GARCH specifications, whether this consists of the conventional GARCH methodology or more advanced models, such as multifractal asymmetric detrended cross-correlation models. An exception is the study of Panagiotidis et al. (2019) that employ Vector Autoregressive (VAR) and Factor Augmented VAR (FAVAR) models for estimations.

Thereby, Dyhrberg (2016a) investigates whether Bitcoin exhibits similar hedging capabilities with gold and if it is appropriate to be used as a medium of exchange. The asymmetric Generalized Autoregressive Conditional Heteroskedasticity (GARCH) specification is adopted for estimations and 
the period under scrutiny covers from 19 July 2010 to 22 May 2015. According to the econometric results derived, Bitcoin can serve as a hedging asset and is mainly suitable for economic units that do not seek for risky investments. To be more precise, Bitcoin exhibits low convergence to the long-run equilibrium as well as clustering phenomena concerning volatility. Moreover, high persistence in volatility is detected, which is similar to what is valid about gold. The demand factor for Bitcoin as a medium of exchange is found to be more influential on Bitcoin prices than shocks. Overall, Bitcoin is found to be a relatively safe asset and could be classified as being somewhere between gold and the US dollar as concerns their medium of exchange until the pure store of value scale of positive characteristics. Moreover, Wu et al. (2019) investigate the hedging and safe-haven capabilities of Bitcoin and gold by employing Generalized Autoregressive Conditional Heteroskedasticity (GARCH) specifications and quantile regression schemes with dummy variables. Estimations take place concerning the period from 2 February 2012 until 31 December 2018. Findings reveal that neither of these two investment assets proves to be a satisfactory hedger against economic policy uncertainty. Moreover, evidence indicates that Bitcoin is more influenced by uncertainty at both lower and higher quantiles whereas gold remains stable with smaller hedge and safe haven coefficients. It should be noted that both of these assets can be useful as weak hedgers and weak safe havens against economic uncertainty regardless of whether markets are in upwards or downwards trends. Therefore, they are found to be appropriate for hedging in investment portfolios.

Furthermore, by another perspective, Kang et al. (2019) investigate the diversification and hedging capacities of gold in comparison to those of Bitcoin. The methodologies of Dynamic Conditional Correlation (DCC) and wavelet coherence are used in order to conduct estimations. The period examined covers from 26 July 2010 until 25 October 2017. Empirical outcomes reveal that the bubble behaviour of gold prices can partly be employed in order to hedge against the bubble behaviour in Bitcoin market values. To be more precise, volatility persistence, causal nexus and alterations across alternative phases are detected as regards gold futures prices and Bitcoin. The closest linkage is traced at a frequency band of 8-16 weeks and during the period from 2012 up to 2015. Contagion between Bitcoin and gold is found to be more intense during the European sovereign debt crisis.

When it comes to more advanced specifications of GARCH methodologies, the academic work of Henriques and Sadorsky (2018); Pal and Mitra (2019) and Gajardo et al. (2018) constitute representative studies.

In their paper, Henriques and Sadorsky (2018) adopt dynamic conditional correlation (DCC), asymmetric DCC (ADCC) and generalized orthogonal Generalized Autoregressive Heteroskedasticity (GO-GARCH) specifications in order to examine the outcomes of replacing gold in a portfolio with Bitcoin. Minimum-variance equity portfolios and both long and short positions are investigated. Data span the period from 4 January 2011 to 31 October 2017. Empirical findings provide evidence that risk-averse investors will be willing to suffer a high performance fee for switching from a portfolio with gold to a portfolio with Bitcoin. It is supported that Bitcoin instead of gold in an investment portfolio could lead to higher risk-adjusted return. In a somewhat similar vein, Pal and Mitra (2019) use conditional volatility estimates of different GARCH methodologies in order to compare optimal hedge ratios between Bitcoin and other financial assets. The period under scrutiny starts from 3 January 2011 and ends at 19 February 2018. Econometric results reveal that the Generalized Orthogonal GARCH (GO-GARCH) specification presents maximum hedging effectiveness. It is supported that 1 US dollar long of Bitcoin could be hedged with 70 cents short of gold. Overall, it is argued that gold provides a better hedge against Bitcoin. By their own perspective, Gajardo et al. (2018) explore the cross-correlations between Bitcoin and traditional assets of primary importance, including gold. In order to conduct estimations, the multifractal asymmetric detrended cross-correlation analysis (MF-DCCA) methodology has been adopted. Examination takes place concerning the period from 13 September 2005 to 25 August 2017. Econometric results provide evidence that multifractality exists in each of the cross-correlations studied, no matter whether gold, crude oil or the Dow Jones Industrial Average (DJIA) index is under scrutiny alongside Bitcoin. Furthermore, asymmetry is detected in 
the cross-correlation exponents under alternative trends of each of the traditional financial assets. The findings reveal that Bitcoin does not behave like any other currency. It should be noted that Bitcoin exhibits greater multifractal spectra on its correlation with gold than what other assets present. Overall, Bitcoin is confirmed to be tightly connected with gold but is not suitable to be classified among conventional assets in terms of investment characteristics.

Moreover, Panagiotidis et al. (2019) look into the effects of shocks stemming from factors such as stock market returns, currency values, gold and oil returns, the Federal Reserve's and the European Central Bank's rates and internet trends on Bitcoin returns. The methodologies they employ constitute a range of VAR and FAVAR schemes. Econometric outcomes provide evidence that shocks to gold positively influence Bitcoin returns, but these findings are not stable over different horizons. Moreover, Bitcoin is revealed to react to oil and stock market shocks as well as to shocks in the foreign exchange markets and the macroeconomy but not so intensely as in the former.

\section{Studies Presenting Outcomes against Bitcoin Sharing Similar Characteristics with Gold}

Literature about the linkage between Bitcoin and gold also breaks down into a third strand of literature that is comprised by studies focusing on the positive and significant nexus among this highly innovative and this highly traditional global assets.

It should be emphasized that a considerable portion of the relative papers employ GARCH specifications in order to study the nexus and characteristics of Bitcoin and gold. More specifically, Baur et al. (2018); Al-Khazali et al. (2018); Klein et al. (2018); Jin et al. (2019) and Symitsi and Chalvatzis (2019) use conventional or advanced GARCH specifications for the purposes of their studies. Arguably, Baur et al. (2018) replicate and extend the analysis of Dyhrberg (2016a) by employing the same sample and econometric methodologies. GARCH and Expenential GARCH specifications are adopted. Outcomes reveal that Bitcoin does not present many similarities with gold neither with fiat money such as the US dollar. This is documented by the differences as concerns the risk-return features, the volatility process and correlation characteristics between Bitcoin and the other assets. Therefore, Bitcoin cannot be categorized as a financial asset that is similar to traditional and well-established means of payments and investments. Furthermore, Al-Khazali et al. (2018) investigated how positive and negative macroeconomic news surprises stemming from large advanced economies influence the returns and volatility of gold and Bitcoin prices. The period examined spans 19 July 2010 until 7 February 2017. GARCH and Exponential GARCH (EGARCH) specifications are employed for estimations. Evidence indicates the existence of an asymmetric effect and that gold exhibits different characteristics to Bitcoin. To be more precise, gold returns and volatility react to surprises and abide by the safe-haven role of gold, while Bitcoin is influenced by surprises to a lesser extent.

When it comes to Klein et al. (2018), they investigate whether or not Bitcoin presents a large number of similarities with gold. In order to make the comparison, they look into the conditional variance properties of these assets and alternative ones for detecting if different structures appear. The asymmetric power ARCH (APARCH) and the Fractionally Integrated APARCH (FIAPARCH) specifications have been adopted for estimations. Furthermore, a BEKK-GARCH framework is employed in order to estimate time-varying conditional correlations. Estimations take place about the 1 July 2011 to 31 December 2017 period. Based on econometric outcomes, it can be observed that Bitcoin and gold present almost completely different characteristics as financial assets and exhibit a different linkages with equity markets. Even though Bitcoin shares some common features with gold and silver regarding their volatility dynamics, there is no evidence that it can act as an efficient safe-haven in investment portfolios. In terms of higher precision, Bitcoin is found to lead to overall lower portfolio returns when included in a portfolio and stock indices are under distress. This comes to contrast with the clear-cut hedging abilities of gold.

Furthermore, Jin et al. (2019) focus their research on investigating whether Bitcoin, gold or crude oil provides better information concerning the volatility of market values of a system consisting of 
these hedging assets. The multifractal detrended cross-correlation analysis (MF- DCCA) framework, alongside multivariate GARCH (MV-GARCH) specifications and information share (IS) analysis, is employed. The period under investigation starts at 10 May 2013 and ends at 7 September 2018. Empirical findings document the obvious existence of multifractality in the cross-correlations between Bitcoin, gold and crude oil. Additionally, there is evidence that Bitcoin is more easily influenced by instability in the prices of gold and crude oil. This is the reason why Bitcoin is found to receive significant spillovers from these markets. Emphasis should be put in that the linkage between Bitcoin and gold in the form of dynamic correlations is nearly negative during the entire period under scrutiny. Overall, gold is found to be a more important determinant than Bitcoin regarding hedging abilities and that information about gold exerts more influence on Bitcoin than the other way around. Generally, it is argued that gold makes a better hedger during stressed times than Bitcoin.

By their own perspective, Symitsi and Chalvatzis (2019) explore by which manner various portfolios consisting of a range of traditional assets are influenced by the inclusion of Bitcoin. Equally weighted portfolios, as well as global minimum-variance portfolios with or without constraints and portfolios with historical and DCC covariance forecasts, are adopted. Moreover, various performance measures are employed for the purposes of investigations. The findings reveal that portfolios that are made of gold, currencies and stocks benefit from adding Bitcoin among its constituents. Therefore, higher profits with no indication of higher risk are presented in alternatively constructed and measured investment portfolios. Bitcoin is found to exhibit low correlation with gold and other assets and its high volatility is not adequate for counterbalancing the beneficial reduction in risk it brings about in each portfolio considered.

Moreover, empirical research has been conducted by employing alternative but also innovative specifications, such as: the multifractal detrended fluctuation analysis, Autoregressive Distributed Lag models and quantile estimations, structural vector autoregressive schemes, Principal Components LASSO (PC-LASSO), the general supremum Augmented Dickey Fuller (GSADF) test, Flexible Least Squares (FLS), and the Conditional Diversification Benefit (CDB) measure.

In their study, Al-Yahyaee et al. (2018) employ the multifractal detrended fluctuation analysis (MF-DFA) approach by Kantelhardt et al. (2002) and the Hurst exponent in order to estimate whether Bitcoin presents higher market efficiency than gold, stock and currency value markets. The period under scrutiny covers from 18 July 2010 until 31 October 2017. The findings support the notion that the Bitcoin market is less efficient than the gold market and the least efficient among the markets examined in general. Thereby, higher speculation opportunities exist when investing in Bitcoin than when gold is preferred by investors. Long-memory features and the presence of multifractality give credence to this conclusion. Bouri et al. (2018) study whether gold and aggregate commodity prices can serve as predicting factors about Bitcoin prices and thereby lead to higher profit for investors. The advanced and quantile Autoregressive Distributed Lag (ARDL) models are employed in order to uncover if non-linear, asymmetric or quantile effects take place from gold and overall commodities to Bitcoin prices. The data under examination are about the 17 July 2010-2 February 2017 period. Empirical results provide evidence towards gold being able to influence the behaviour of Bitcoin market values. Emphasis is given in that Bitcoin and gold present an asymmetric, non-linear nexus that is not the same across quantiles. The complex nature of this relation suggests that non-conventional cointegration methodologies better explain long-run linkages between Bitcoin and gold. Moreover, it is argued that the differences between them are more obvious in extreme cases, that is lower or upper quantiles. Moreover, Das et al. (2019) investigate the intensity of the hedging and safe-haven capacities of Bitcoin in relation to the corresponding abilities of gold. Econometric estimations take place by employing GARCH schemes and quantile regressions. The period under scrutiny spans from 20 July 2010 until 20 June 2019. The framework of analysis is centered on determining which asset is more appropriate for hedging against crude oil volatility (OVX) and structural crude oil shocks where structural vector autoregressive (SVAR) analysis has been applied. Evidence supports that Bitcoin does not constitute 
the best hedger against such shocks. More specifically, Bitcoin exhibits better abilities than gold as concerns hedging OVX but is an inferior safe haven than gold in extreme conditions.

Panagiotidis et al. (2020) employ principal component-guided sparce regression (PC-LASSO) methodologies in order to investigate the significance of fourty-one potential covariates of Bitcoin returns during the period 2010-2018. Moreover, the GSADF test for bubbles by Phillips et al. (2015) and the FLS models by Kalaba and Tesfatsion (1989) are adopted. The findings indicate that commodities such as gold are not influential on Bitcoin returns. It is revealed that economic policy uncertainty, stock market volatility and government bond yields affect Bitcoin. So does the foreign exchange market but to a lesser extent. Moreover, bubble behaviour is detected in the Bitcoin market. In their study, Shahzad et al. (2019a) conducted comparisons between Bitcoin and gold as regards their hedging and safe-haven characteristics against the G7 stock markets. The CDB measure depending on the threshold probability by Christoffersen et al. (2018) is employed in terms of the expected shortfall for probabilities. Data span the period from 20 July 2010 to 31 December 2018. Econometric outcomes bring about stronger results concerning the hedging and safe-haven properties of gold as this is found to be influential against the G7 stock markets. When it comes to Bitcoin, evidence mainly indicates that it is efficient against the Canadian stock index. Overall, it can be supported that dissimilarities concerning the hedging capabilities of Bitcoin and gold are noteworthy. This happens because gold is an effective hedger against a much larger spectrum of countries (France, Germany, Italy, Japan, the United Kingdom, the United States as well as the MSCI G7 index) compared to Bitcoin.

\section{Economic Implications and Conclusions}

The shortage of liquidity presented nowadays (Avdjiev et al. 2020; Etula et al. 2020) has aroused increasing concerns among governments, regulators, investors, speculators and the financial press about the existence of alternative forms of money and liquidity similar to traditional ones. Since the skyrocketing increase in market values of cryptocurrencies during 2017, the highly promising Bitcoin digital currency has been the epicenter of relevant debate. This is the reason why the analysis of Bitcoin characteristics in comparison to gold is advancing at high speed.

This study undertakes the strenuous task to provide in the most representative extent the nexus between Bitcoin and gold according to what empirical research has resulted in up to the present. In order to accomplish this, twenty-two empirical studies published in high-quality journals have been used in this analysis for providing the full spectrum of empirical findings. For the purposes of estimations, innovative methodologies have been employed from primary studies. Thereby, the nexus between Bitcoin and gold is investigated by Multifractal Detrended Fluctuation Analysis (MF-DFA), the Non-linear Autoregressive Distributed Lag (NARDL) and Quantile Autoregressive Distributed Lag (QARDL) models, Vector Autoregression (VAR), Factor Augmented VAR (FAVAR) and Structural VAR(SVAR), Quantile-on-quantile regression (QQR), and bivariate cross-quantilograms. Furthermore, dynamic Markov-switching copula methodologies, the CDB measure, Least Absolute Shrinkage and Selection Operator (LASSO) approaches and the identification of multiple bubbles by Phillips et al. (2015) models have been employed.

Moreover, a spectrum of GARCH specifications has been employed. GARCH, Dummy Variable GARCH, Exponential GARCH, Threshold GARCH, Asymmetric Power ARCH (APARCH), Fractionally Integrated APARCH (FIAPARCH), Generalized Orthogonal GARCH (GO-GARCH) and Baba-Engle-Kraft-Kroner GARCH (BEKK-GARCH) models have been adopted. As regards dynamic conditional correlations, the Dynamic Conditional Correlations GARCH (DCC-GARCH), the asymmetric DCC-GARCH (ADCC-GARCH), Multifractal Detrended Cross-Correlation Analysis (MF-DCCA) as well as the Asymmetric Generalized Dynamic Conditional Correlation GARCH (AGDCC-GARCH) schemes are used.

Econometric outcomes extracted by primary studies reveal that Bitcoin shares common characteristics with traditional assets such as gold, stock indices and oil. More specifically, when focusing interest on its nexus with gold, there is evidence that Bitcoin exhibits low or negative correlation with 
it, while there are also findings about an asymmetric and non-linear linkage between them. The main differences between Bitcoin and gold are detected in their risk-return trade-off when included in portfolios as well as concerning their volatility and correlations. These differences are more discernible during extreme conditions, such as bull or bear markets. It should be noted that Bitcoin is found to be a good hedger against oil and stock indices but not to an extent as large as gold is. Nevertheless, it acts efficiently in portfolios with conventional assets where risk needs to be lower without returns being diminished at the same time. It can be underlined that gold is more stable regarding its safe-haven characteristics and acts more efficiently as a hedger during out of the ordinary economic conditions.

Overall, it can be supported that Bitcoin is an asset between gold and the US dollar and the Bitcoin market should mature by a much larger level in order for the Bitcoin to be comparable to gold concerning its global safe-haven properties. Thereby, Bitcoin has to make quantum leaps forward regarding its popularity to economic units in order to be included in investor portfolios as willingly as they prefer gold during stressed periods.

This integrated survey analyzes the preponderant issue of whether Bitcoin could render a world-wide accepted means of payments and investment as gold. Emphasis is put on the level of similarities and hedging abilities that these two major assets exhibit. Evidence reveals that Bitcoin presents several resemblances with this traditional safe-haven asset. Nevertheless, it needs to be infused into investors' beliefs by a much larger degree in order to render a traditional weapon in the arsenal against high volatility and the risk of losses during turbulent times in the global financial system. Therefore, the findings suggest that digitalization in payment systems should be encouraged and further developed in order for digital currencies to become widely accepted forms of liquidity.

This paper provides a roadmap for further vivid academic research on the perspectives of virtual forms of money in the financial system in a worldwide level. This study could help to advance this highly debated and quickly upcoming strand of macro-financial literature. Avenues for future research could include studying the nexus between alternative cryptocurrencies or stablecoins with gold or similar safe-haven assets, such as silver.

Funding: This research received no external funding.

Acknowledgments: This survey is written for the purposes of the post-doctoral thesis of the author. The latter is indebted to Stephanos Papadamou for useful guidance and his overall help during the writing of this study.

Conflicts of Interest: The author declare no conflict of interest.

\section{Appendix A}

Table A1. Main characteristics of primary studies on the nexus between Bitcoin and gold.

\begin{tabular}{|c|c|c|c|c|}
\hline Authors & Source & Time Period & Methodology & Findings \\
\hline Al-Yahyaee et al. (2018) & $\begin{array}{l}\text { Coindesk.com } \\
\text { Datastream }\end{array}$ & $\begin{array}{c}18 \text { July } 2010-31 \\
\text { October } 2017\end{array}$ & $\begin{array}{l}\text { Multifractal Detrended } \\
\text { Fluctuation Analysis } \\
\text { (MF-DFA) by } \\
\text { Kantelhardt et al. (2002) } \\
\text { Hurst exponent }\end{array}$ & $\begin{array}{l}\text { Bitcoin market is less efficient than the } \\
\text { gold market and the least efficient } \\
\text { among the markets examined }\end{array}$ \\
\hline
\end{tabular}


Table A1. Cont.

\begin{tabular}{|c|c|c|c|c|}
\hline Authors & Source & Time Period & Methodology & Findings \\
\hline Bouoiyour et al. (2019) & $\begin{array}{l}\text { Coindesk.com } \\
\text { FRED database }\end{array}$ & $\begin{array}{l}18 \text { July 2010-31 } \\
\text { March } 2018\end{array}$ & $\begin{array}{c}\text { Dynamic } \\
\text { Markov-switching } \\
\text { copula model based on } \\
\text { Patton (2006) } \\
\text { BDS test by Broock et al. } \\
\text { (1996) }\end{array}$ & $\begin{array}{l}\text { Gold exhibits diversifying benefits for } \\
\text { investors in digital assets but Bitcoin } \\
\text { is more capable of efficiently } \\
\text { transferring value }\end{array}$ \\
\hline Dyhrberg (2016a) & $\begin{array}{l}\text { Coindesk.com } \\
\text { Datastream } \\
\text { Federal Reserve } \\
\text { Bank of New York }\end{array}$ & $\begin{array}{l}19 \text { July 2010-22 } \\
\text { May } 2015\end{array}$ & $\begin{array}{c}\text { GARCH by Bollerslev } \\
\text { (1986)(miao) Exponential } \\
\text { GARCH by Nelson } \\
\text { (1991) }\end{array}$ & $\begin{array}{l}\text { Bitcoin can serve as a hedging asset } \\
\text { especially for risk-averse investors } \\
\text { High persistence in volatility is } \\
\text { detected, which is similar to what is } \\
\text { valid about gold }\end{array}$ \\
\hline Dyhrberg (2016b) & $\begin{array}{l}\text { Coindesk.com } \\
\text { Datastream }\end{array}$ & $\begin{array}{l}19 \text { July 2010-22 } \\
\text { May } 2015\end{array}$ & $\begin{array}{l}\text { Threshold GARCH by } \\
\text { Glosten et al. (1993) }\end{array}$ & $\begin{array}{l}\text { Bitcoin constitutes an efficient hedger } \\
\text { and presents significantly similar } \\
\text { features with gold }\end{array}$ \\
\hline Jin et al. (2019) & $\begin{array}{l}\text { Coinmarketcap.com } \\
\text { Federal Reserve } \\
\text { Bank of St. Louis } \\
\text { Energy Information } \\
\text { Administration } \\
\text { (EIA) }\end{array}$ & $\begin{array}{c}10 \text { May } 2013-7 \\
\text { September } 2018\end{array}$ & $\begin{array}{l}\text { Multifractal Detrended } \\
\text { Cross-Correlation } \\
\text { Analysis (MF-DCCA) } \\
\text { Multivariate Generalized } \\
\text { Autoregressive } \\
\text { Conditional } \\
\text { Heteroskedasticity } \\
\text { (MV-GARCH) } \\
\text { Information Share (IS) } \\
\text { analysis as in Hasbrouck } \\
(1995,2002)\end{array}$ & $\begin{array}{c}\text { The linkage between Bitcoin and gold } \\
\text { in the form of dynamic correlations is } \\
\text { nearly negative } \\
\text { Gold makes a better hedger during } \\
\text { stressed times than Bitcoin }\end{array}$ \\
\hline
\end{tabular}


Table A1. Cont.

\begin{tabular}{|c|c|c|c|c|}
\hline Authors & Source & Time Period & Methodology & Findings \\
\hline Klein et al. (2018) & $\begin{array}{l}\text { Coindesk.com } \\
\text { Datastream }\end{array}$ & $\begin{array}{l}1 \text { July 2011-31 } \\
\text { December } 2017\end{array}$ & $\begin{array}{c}\text { Asymmetric Power } \\
\text { ARCH (APARCH) by } \\
\text { Ding et al. (1993) } \\
\text { Fractionally Integrated } \\
\text { APARCH (FIAPARCH) } \\
\text { by Tse (1998) } \\
\text { Baba-Engle-Kraft-Kroner } \\
\text { GARCH } \\
\text { (BEKK-GARCH) by } \\
\text { Engle and Kroner (1995) }\end{array}$ & $\begin{array}{l}\text { Bitcoin and gold present almost } \\
\text { completely different characteristics as } \\
\text { financial assets and exhibit different } \\
\text { type of nexus with equity markets }\end{array}$ \\
\hline Pal and Mitra (2019) & $\begin{array}{l}\text { Yahoo Finance } \\
\text { Datastream }\end{array}$ & $\begin{array}{l}3 \text { January } \\
2011-19 \\
\text { February } 2018\end{array}$ & $\begin{array}{c}\text { DCC-GARCH based on } \\
\text { Engle (2002) and } \\
\text { Bollerslev (1986) } \\
\text { Asymmetric } \\
\text { DCC-GARCH } \\
\text { (ADCC-GARCH) by } \\
\text { Cappiello et al. (2006) } \\
\text { Generalized Orthogonal } \\
\text { GARCH (GO-GARCH) } \\
\text { by Van der Weide (2002) } \\
\text { Optimal hedge ratios as } \\
\text { in Kroner and Sultan } \\
\text { (1993) }\end{array}$ & $\begin{array}{c}1 \text { US dollar long of Bitcoin could be } \\
\text { hedged with } 70 \text { cents short of gold. } \\
\text { Gold provides a better hedge against } \\
\text { Bitcoin }\end{array}$ \\
\hline $\begin{array}{l}\text { Panagiotidis et al. } \\
\text { (2018) }\end{array}$ & $\begin{array}{c}\text { Coindesk.com } \\
\text { Quandl } \\
\text { us.spindices.com } \\
\text { policyuncertainty.com } \\
\text { R package } \\
\text { 'gtrendsR' } \\
\text { R package } \\
\text { 'wikipediatrend' } \\
\text { tools.wmflabs.org }\end{array}$ & $\begin{array}{l}17 \text { June 2010-23 } \\
\text { June 2017 }\end{array}$ & $\begin{array}{l}\text { Glmnet and lars Least } \\
\text { Absolute Shrinkage and } \\
\text { Selection Operator } \\
\text { (LASSO) based on } \\
\text { Tibshirani (1996) }\end{array}$ & $\begin{array}{l}\text { Bitcoin is positively and strongly } \\
\text { affected by gold }\end{array}$ \\
\hline $\begin{array}{l}\text { Panagiotidis et al. } \\
\qquad(2020)\end{array}$ & $\begin{array}{c}\text { Coindesk.com } \\
\text { Thomson Reuters } \\
\text { Eikon } \\
\text { R package } \\
\text { 'wikipediatrend' } \\
\text { tools.wmflabs.org/page } \\
\text { views }\end{array}$ & $\begin{array}{l}21 \text { July 2010-31 } \\
\text { May 2018 }\end{array}$ & $\begin{array}{c}\text { Least Absolute } \\
\text { Shrinkage and Selection } \\
\text { Operator (LASSO) based } \\
\text { on Tibshirani (1996) and } \\
\text { Principal } \\
\text { component-guided } \\
\text { sparse regression } \\
\text { (PC-LASSO) LASSO } \\
\text { (PC-LASSO) by Tay et al. } \\
\text { (2018) } \\
\text { Flexible Least Squares } \\
\text { FLS models by Kalaba } \\
\text { and Tesfatsion (1989) } \\
\text { Rolling window } \\
\text { generalized supremum } \\
\text { Augmented } \\
\text { Dickey-Fuller test for } \\
\text { bubbles (GSADF) by } \\
\text { Phillips et al. (2015) }\end{array}$ & $\begin{array}{l}\text { Commodities such as gold are not } \\
\text { influential on Bitcoin returns }\end{array}$ \\
\hline
\end{tabular}


Table A1. Cont.

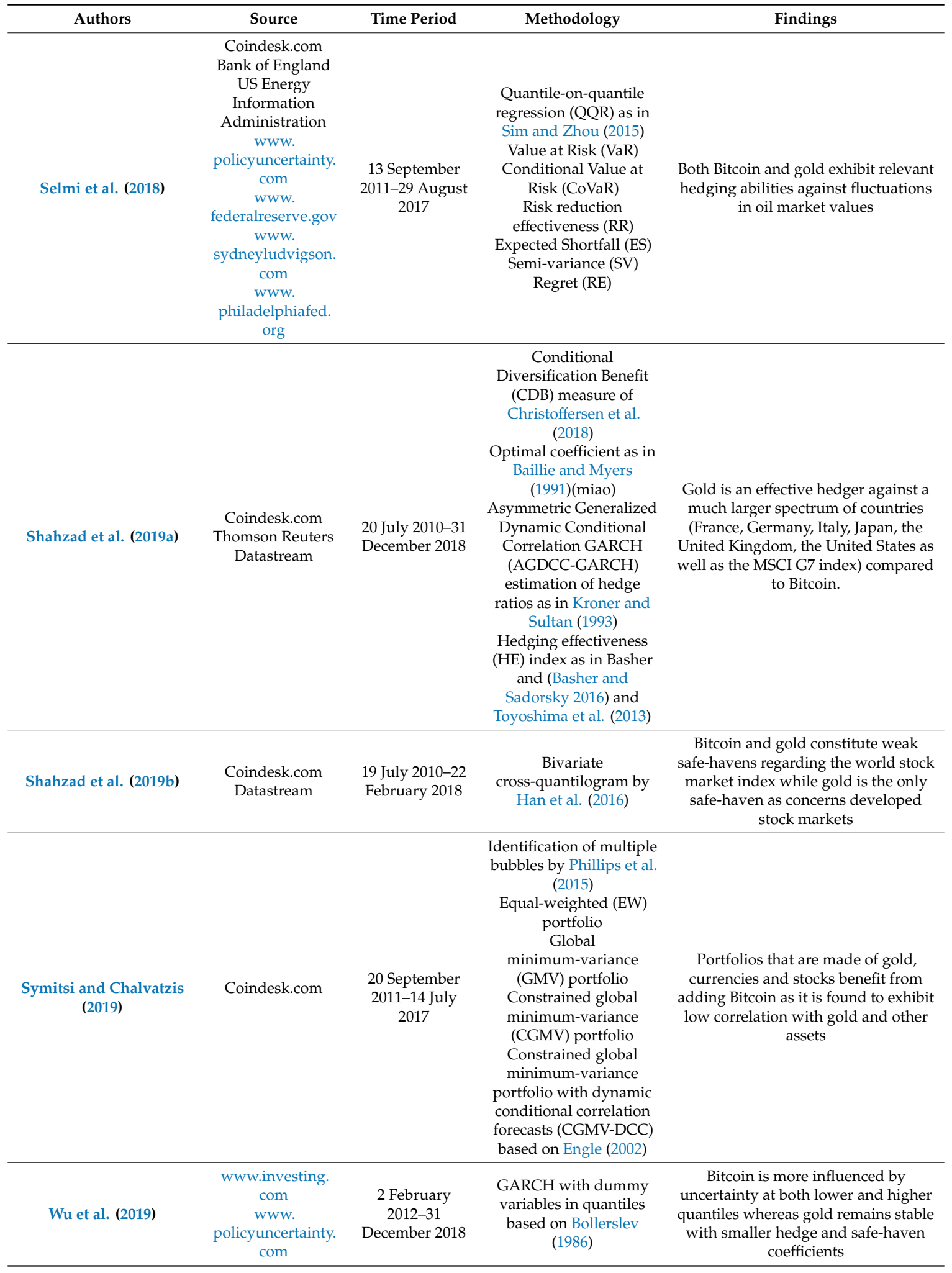




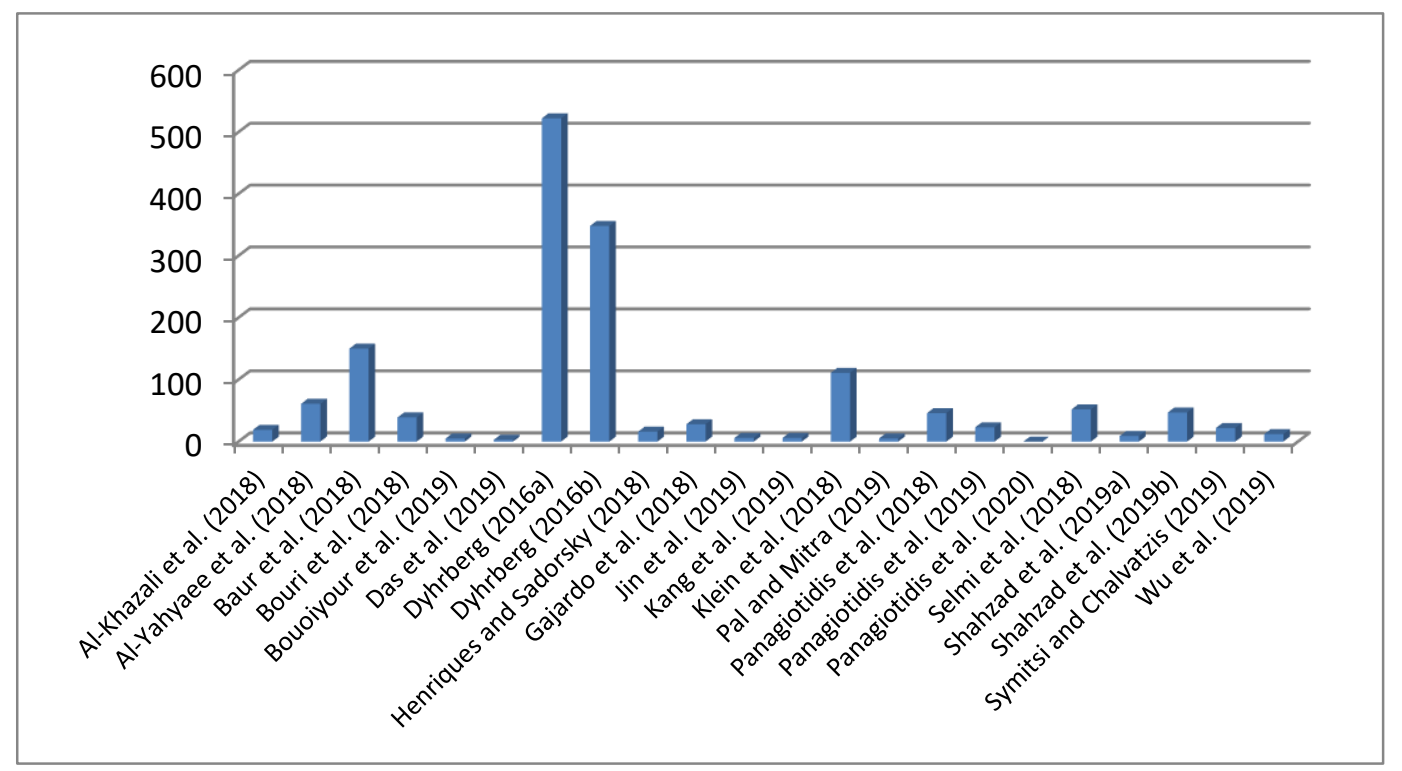

Figure A1. Citations by Google Scholar of studies investigating the nexus between Bitcoin and gold (as of 12 April 2020).

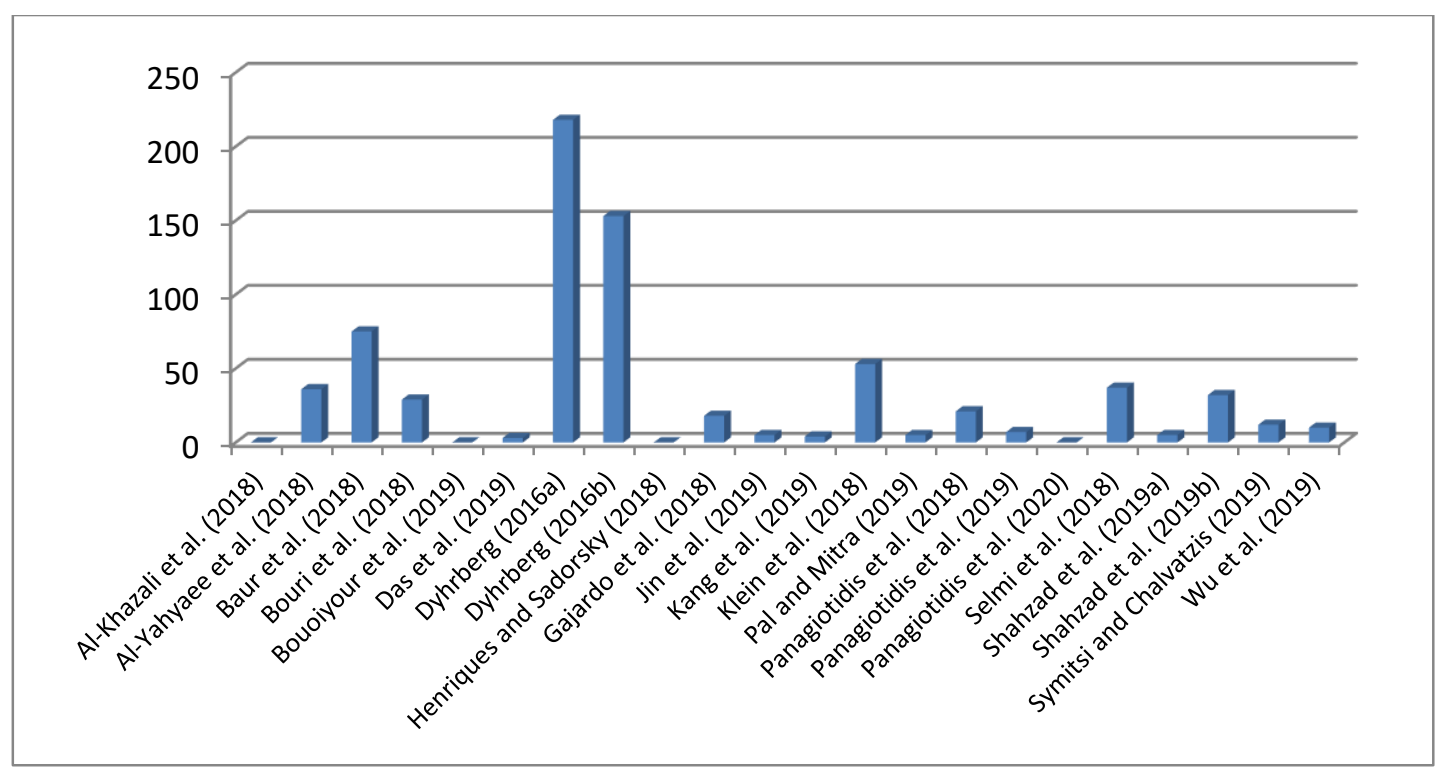

Figure A2. Citations by Plum-X metrics of studies investigating the nexus between Bitcoin and gold (as of 12 April 2020). 


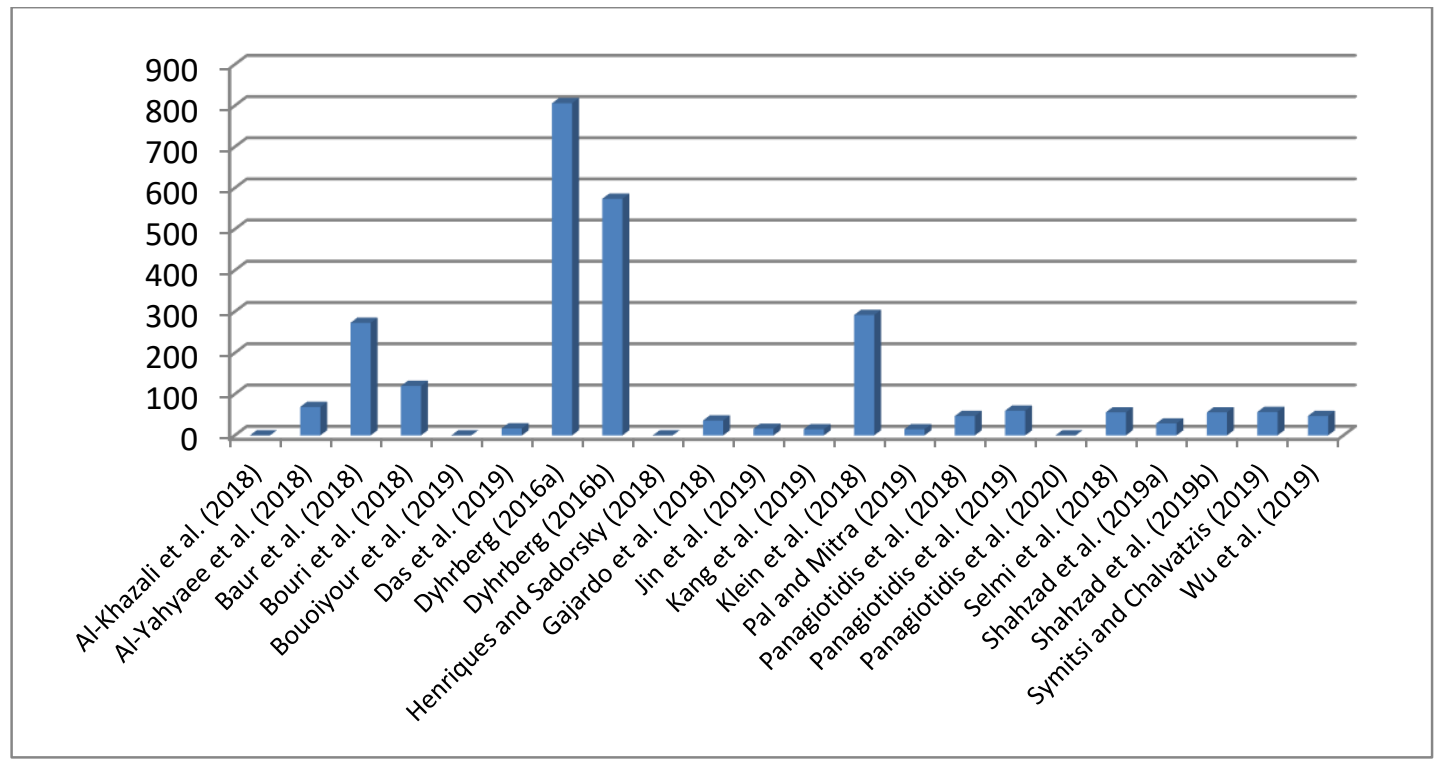

Figure A3. Captures by Plum-X metrics of studies investigating the nexus between Bitcoin and gold (as of 12 April 2020).

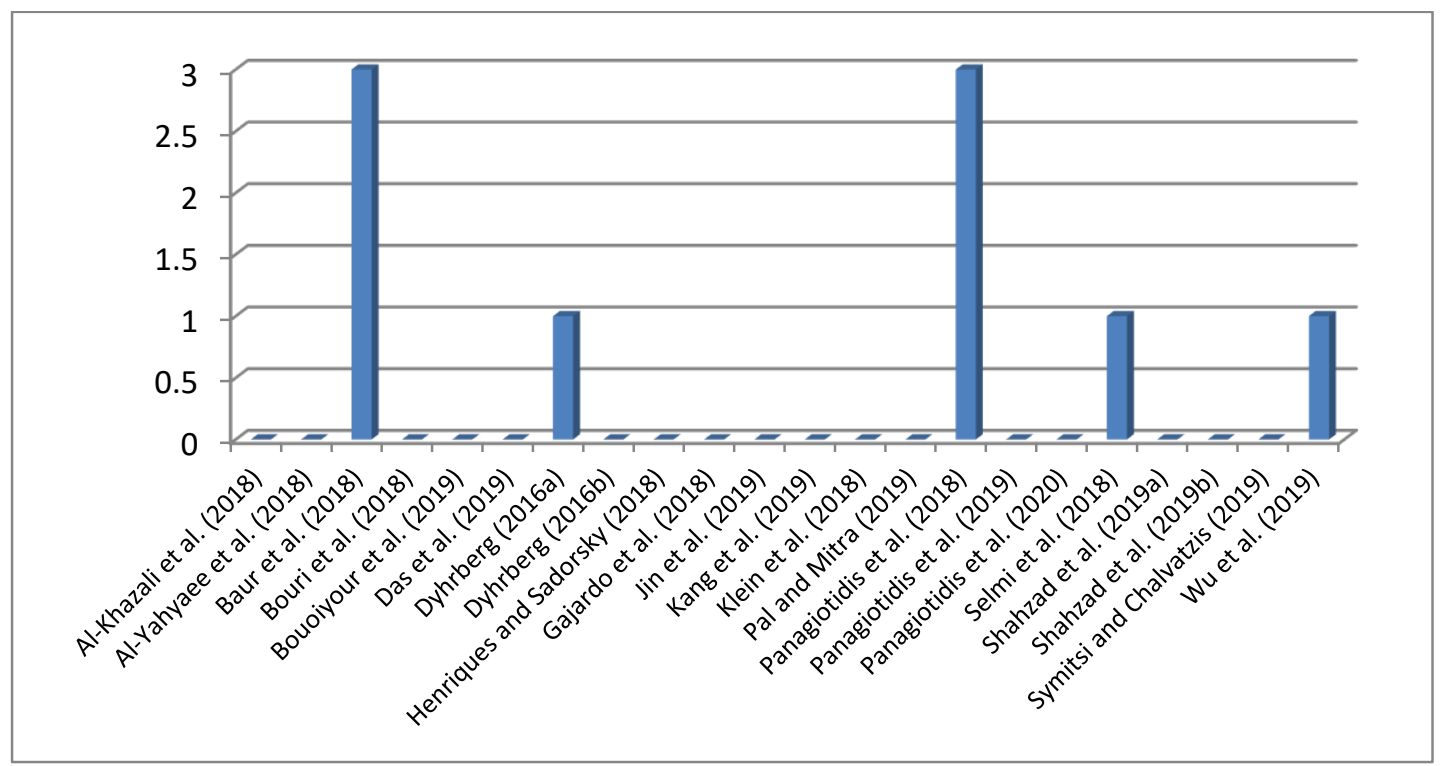

Figure A4. Mentions by Plum-X metrics of studies investigating the nexus between Bitcoin and gold (as of 12 April 2020). 


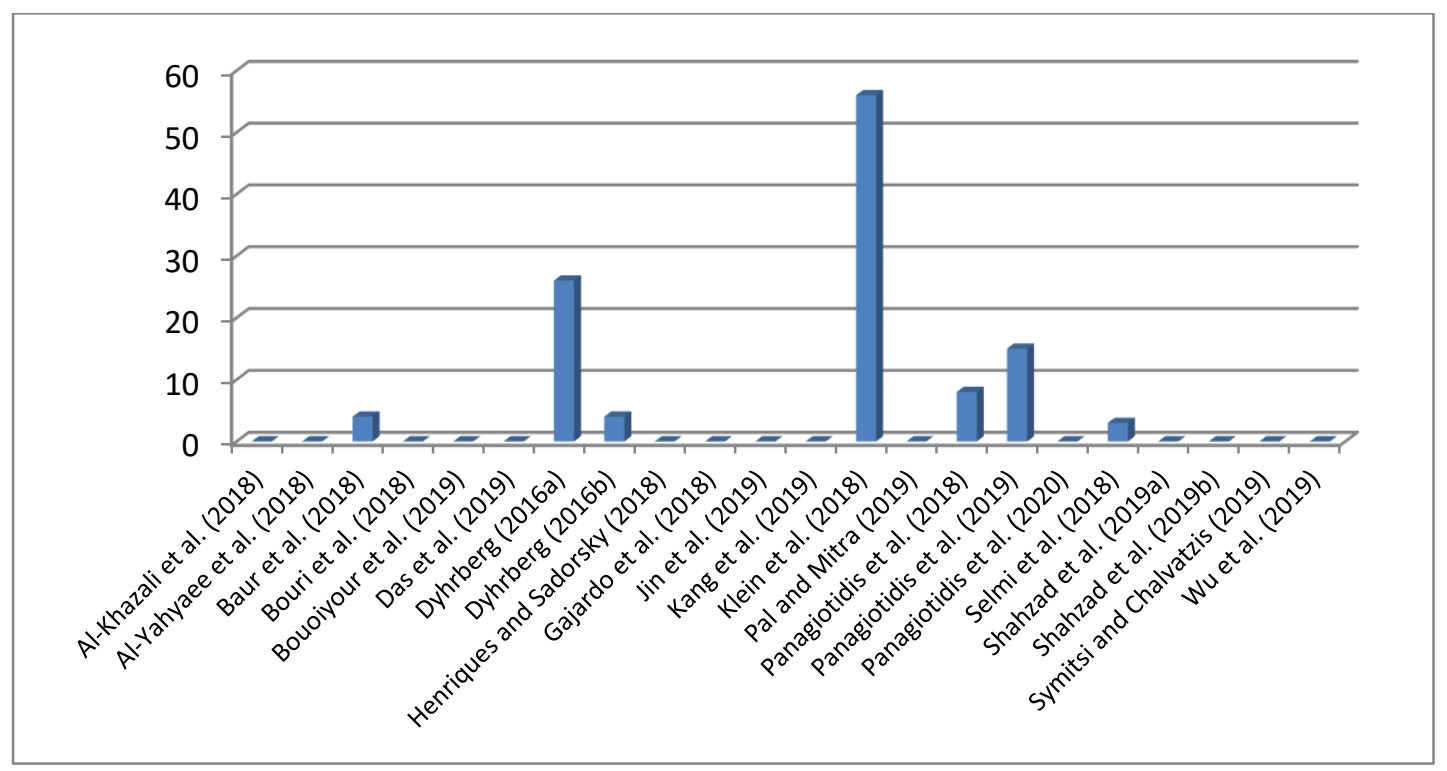

Figure A5. Social Media Plum-X metrics of studies investigating the nexus between Bitcoin and gold (as of 12 April 2020).

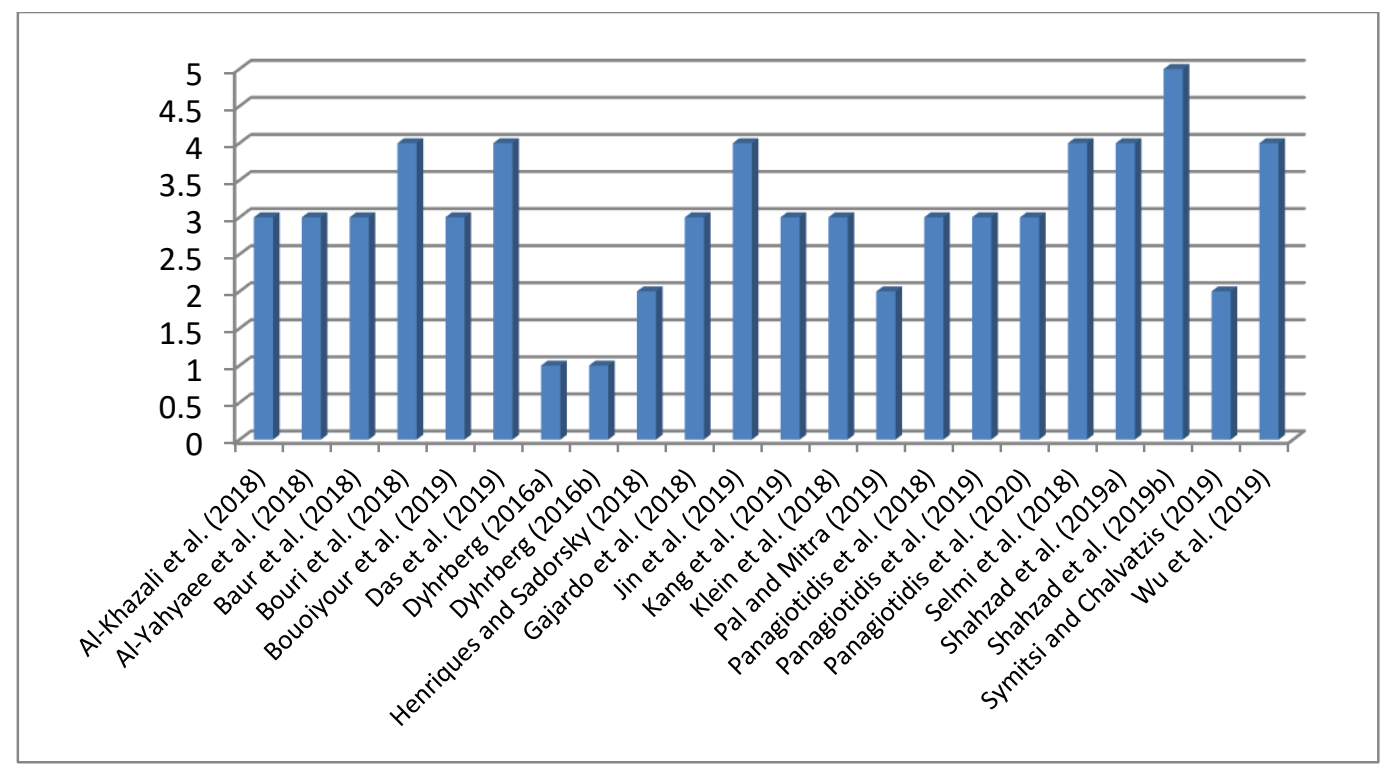

Figure A6. Number of authors in each study. 


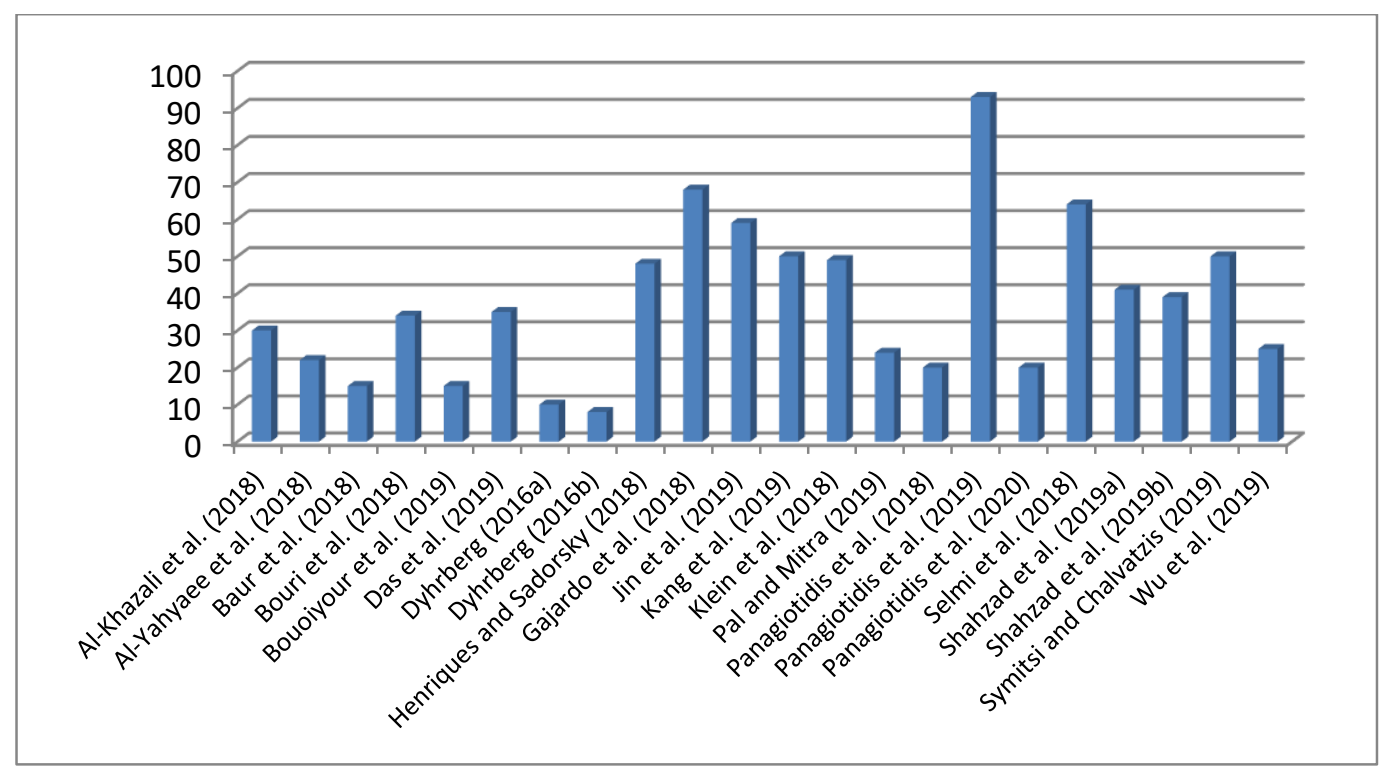

Figure A7. Number of academic references employed in each study.

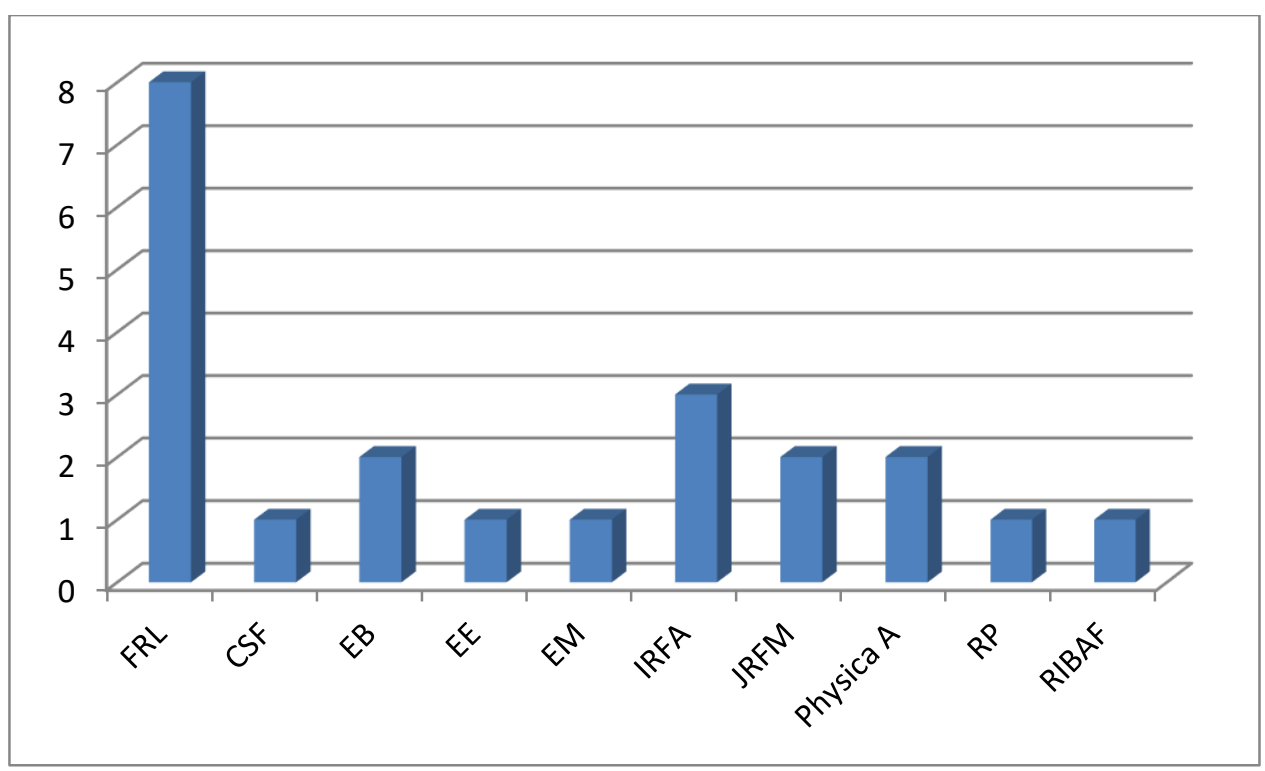

Figure A8. Journals in which academic papers about the nexus between Bitcoin and gold have been published. Note: FRL, CSF, EB, EE, EM, IRFA, JRFM, Physica A, RP and RIBAF stand for Finance Research Letters, Chaos, Solitons \& Fractals, Economics Bulletin, Energy Economics, Economic Modelling International Review of Financial Analysis, Journal of Risk and Financial Management, Physica A: Statistical Mechanics and its Applications, Resources Policy, and Research in International Business and Finance, respectively. 


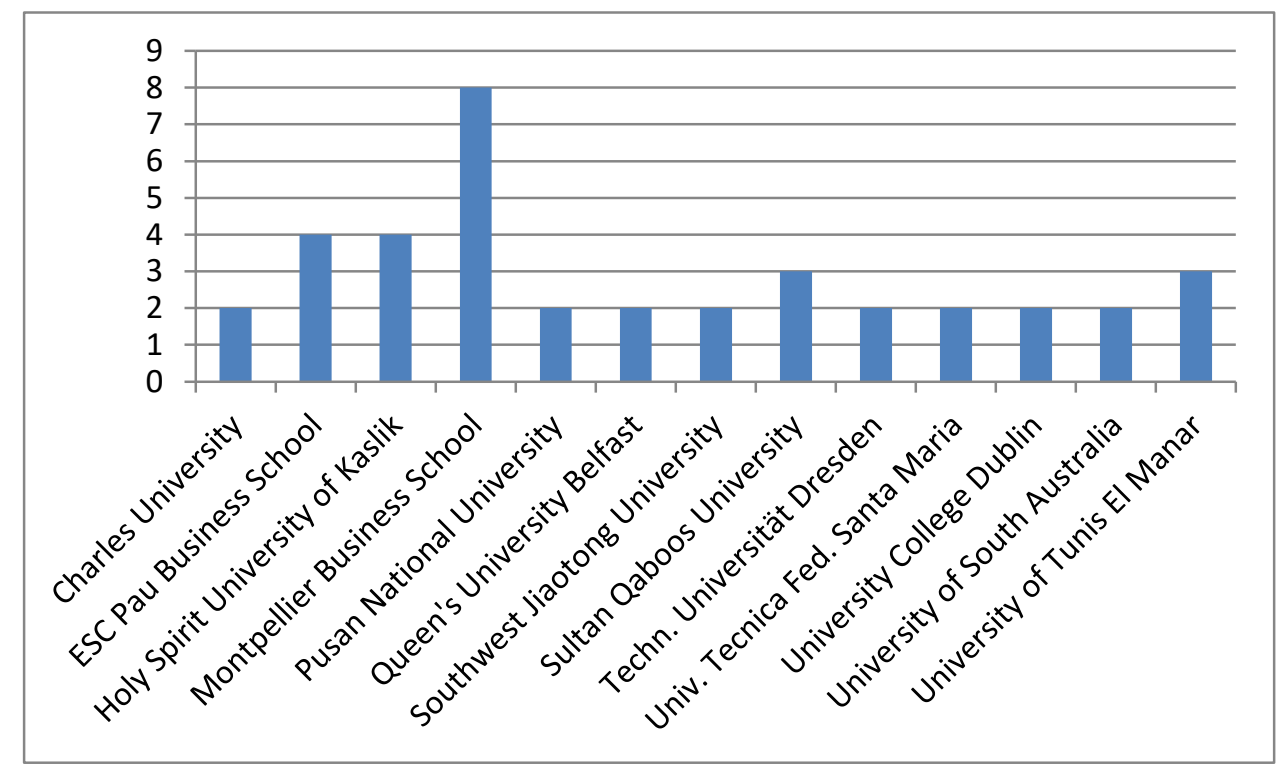

Figure A9. Number of times where researchers of universities are found to be authors in the studies investigated.

\section{References}

Al-Khazali, O., B. Elie, and D. Roubaud. 2018. The impact of positive and negative macroeconomic news surprises: Gold versus Bitcoin. Economics Bulletin 38: 373-82.

Al-Yahyaee, K. H., W. Mensi, and S. M. Yoon. 2018. Efficiency, multifractality, and the long-memory property of the Bitcoin market: A comparative analysis with stock, currency, and gold markets. Finance Research Letters 27: 228-34. [CrossRef]

Ammous, S. 2018. Can cryptocurrencies fulfil the functions of money? The Quarterly Review of Economics and Finance 70: 38-51. [CrossRef]

Avdjiev, S., L. Gambacorta, L. S. Goldberg, and S. Schiaffi. 2020. The shifting drivers of global liquidity. Journal of International Economics, 103324. [CrossRef]

Baillie, R. T., and R. J. Myers. 1991. Bivariate GARCH estimation of the optimal commodity futures hedge. Journal of Applied Econometrics 6: 109-24. [CrossRef]

Basher, S. A., and P. Sadorsky. 2016. Hedging emerging market stock prices with oil, gold, VIX, and bonds: A comparison between DCC, ADCC and GO-GARCH. Energy Economics 54: 235-47. [CrossRef]

Baur, D. G., and B. M. Lucey. 2010. Is gold a hedge or a safe haven? An analysis of stocks, bonds and gold. Financial Review 45: 217-29. [CrossRef]

Baur, D. G., T. Dimpfl, and K. Kuck. 2018. Bitcoin, gold and the US dollar-A replication and extension. Finance Research Letters 25: 103-10. [CrossRef]

Beneki, C., A. Koulis, N. A. Kyriazis, and S. Papadamou. 2019. Investigating volatility transmission and hedging properties between Bitcoin and Ethereum. Research in International Business and Finance 48: 219-27. [CrossRef]

Böhme, R., N. Christin, B. Edelman, and T Moore. 2015. Bitcoin: Economics, technology, and governance. Journal of Economic Perspectives 29: 213-38. [CrossRef]

Bollerslev, T. 1986. Generalized autoregressive conditional heteroskedasticity. Journal of Econometrics 31: 307-27. [CrossRef]

Bouoiyour, J., R. Selmi, and M. E. Wohar. 2019. Bitcoin: competitor or complement to gold? Economics Bulletin 39: 186-91.

Bouri, E., R. Gupta, A. Lahiani, and M. Shahbaz. 2018. Testing for asymmetric nonlinear short-and long-run relationships between bitcoin, aggregate commodity and gold prices. Resources Policy 57: 224-35. [CrossRef]

Broock, W. A., J. A. Scheinkman, W. D. Dechert, and B. LeBaron. 1996. A test for independence based on the correlation dimension. Econometric Reviews 15: 197-235. [CrossRef]

Cappiello, L., R. F. Engle, and K. Sheppard. 2006. Asymmetric dynamics in the correlations of global equity and bond returns. Journal of Financial Econometrics 4: 537-72. [CrossRef] 
Cho, J. S., T. H. Kim, and Y. Shin. 2015. Quantile cointegration in the autoregressive distributed-lag modeling framework. Journal of Econometrics 188: 281-300. [CrossRef]

Christoffersen, P., K. Jacobs, X. Jin, and H. Langlois. 2018. Dynamic dependence and diversification in corporate credit. Review of Finance 22: 521-60. [CrossRef]

Corbet, S., B. Lucey, A. Urquhart, and L. Yarovaya. 2019. Cryptocurrencies as a financial asset: A systematic analysis. International Review of Financial Analysis 62: 182-99. [CrossRef]

Das, D., C. L. Le Roux, R. K. Jana, and A. Dutta. 2019. Does Bitcoin hedge crude oil implied volatility and structural shocks? A comparison with gold, commodity and the US Dollar. Finance Research Letters, 101335. [CrossRef]

Ding, Z., C. W. Granger, and R. F. Engle. 1993. A long memory property of stock market returns and a new model. Journal of Empirical Finance 1: 83-106. [CrossRef]

Dyhrberg, Anne H. 2016a. Bitcoin, gold and the dollar-A GARCH volatility analysis. Finance Research Letters 16: 85-92. [CrossRef]

Dyhrberg, Anne H. 2016b. Hedging capabilities of bitcoin. Is it the virtual gold? Finance Research Letters 16: 139-44. [CrossRef]

Engle, Robert. 2002. Dynamic conditional correlation: A simple class of multivariate generalized autoregressive conditional heteroskedasticity models. Journal of Business E Economic Statistics 20: 339-50.

Engle, Robert F., and Kroner F. Kroner. 1995. Multivariate simultaneous generalized ARCH. Econometric Theory 11: 122-50. [CrossRef]

Elton, Edwin J., and Martin J. Gruber. 1997. Modern portfolio theory, 1950 to date. Journal of Banking E Finance 21: 1743-59.

Etula, Etula, Kalle Rinne, Matti Suominen, and Lauri Vaittinen. 2020. Dash for cash: Monthly market impact of institutional liquidity needs. The Review of Financial Studies 33: 75-111. [CrossRef]

Fang, Fan, Camine Ventre, Michail Basios, Hoiliong Kong, Leslie Kanthan, Lingbo Li, David Martinez-Regoband, and Fan Wu. 2020. Cryptocurrency Trading: A Comprehensive Survey. arXiv.

Fassas, Athanasios. P, Stephano Papadamou, and Alexandros Koulis. 2020. Price discovery in bitcoin futures. Research in International Business and Finance 52: 101116. [CrossRef]

Fischer, Thomas Gunter, Christopher Krauss, and Alexander Deinert. 2019. Statistical arbitrage in cryptocurrency markets. Journal of Risk and Financial Management 12: 31. [CrossRef]

Gajardo, Gabriel, Werner D. Kristjanpoller, and Marcel Minutolo. 2018. Does Bitcoin exhibit the same asymmetric multifractal cross-correlations with crude oil, gold and DJIA as the Euro, Great British Pound and Yen? Chaos Solitons E Fractals 109: 195-205.

Gans, Joshua S., and Hanna Halaburda. 2015. Some economics of private digital currency. In Economic Analysis of the Digital Economy. Chicago: University of Chicago Press, pp. 257-76.

Glosten, Lawrence. R., Ravi Jagannathan, and Davide E. Runkle. 1993. On the relation between the expected value and the volatility of the nominal excess return on stocks. The Journal of Finance 48: 1779-801. [CrossRef]

Han, Han, Oliver Linton, Tatsushi Oka, and Yoon Jae Whang. 2016. The cross-quantilogram: Measuring quantile dependence and testing directional predictability between time series. Journal of Econometrics 193: 251-70. [CrossRef]

Hasbrouck, J. 1995. One security, many markets: Determining the contributions to price discovery. The Journal of Finance 50: 1175-99. [CrossRef]

Hasbrouck, J. 2002. Stalking the "efficient price" in market microstructure specifications: an overview. Journal of Financial Markets 5: 329-39. [CrossRef]

Henriques, I., and P. Sadorsky. 2018. Can bitcoin replace gold in an investment portfolio? Journal of Risk and Financial Management 11: 48. [CrossRef]

Jin, J., J. Yu, Y. Hu, and Y. Shang. 2019. Which one is more informative in determining price movements of hedging assets? Evidence from Bitcoin, gold and crude oil markets. Physica A Statistical Mechanics and Its Applications 527: 121121. [CrossRef]

Kalaba, R., and L. Tesfatsion. 1989. Time-varying linear regression via flexible least squares. Computers $\mathcal{E}$ Mathematics with Applications 17: 1215-45.

Kang, S. H., R. P McIver, and J. A. Hernandez. 2019. Co-movements between Bitcoin and Gold: A wavelet coherence analysis. Physica A Statistical Mechanics and Its Applications 536: 120888. [CrossRef] 
Kantelhardt, J. W., S. A. Zschiegner, E. Koscielny-Bunde, S. Havlin, A Bunde, and H. E. Stanley. 2002. Multifractal detrended fluctuation analysis of nonstationary time series. Physica A Statistical Mechanics and Its Applications 316: 87-114. [CrossRef]

Klein, Thomas, Hien Pham Thu, and Thomas Walther. 2018. Bitcoin is not the New Gold-A comparison of volatility, correlation, and portfolio performance. International Review of Financial Analysis 59: 105-16. [CrossRef]

Kroner, K. F., and J. Sultan. 1993. Time-varying distributions and dynamic hedging with foreign currency futures. Journal of Financial and Quantitative Analysis 28: 535-51. [CrossRef]

Kyriazis, N. A. 2019a. A survey on efficiency and profitable trading opportunities in cryptocurrency markets. Journal of Risk and Financial Management 12: 67. [CrossRef]

Kyriazis, N. A. 2019b. A Survey on Empirical Findings about Spillovers in Cryptocurrency Markets. Journal of Risk and Financial Management 12: 170. [CrossRef]

Kyriazis, N. A., and P. Prassa. 2019. Which Cryptocurrencies Are Mostly Traded in Distressed Times? Journal of Risk and Financial Management 12: 135. [CrossRef]

Kyriazis, N, A. K. Daskalou, M. Arampatzis, P. Prassa, and E. Papaioannou. 2019. Estimating the volatility of cryptocurrencies during bearish markets by employing GARCH models. Heliyon 5: e2239. [CrossRef]

Maese, V. A., A. W. Avery, B. A. Naftalis, S. P. Wink, and Y. D. Valdez. 2016. Cryptocurrency: A Primer. Banking LJ 133: 468.

Nelson, D. B. 1991. Conditional heteroskedasticity in asset returns: A new approach. Econometrica: Journal of the Econometric Society 59: 347-70. [CrossRef]

O'Connor, F. A., B. M. Lucey, J. A. Batten, and D. G. Baur. 2015. The financial economics of gold-A survey. International Review of Financial Analysis 41: 186-205. [CrossRef]

Pal, Debdatta, and Subrata K. Mitra. 2019. Hedging bitcoin with other financial assets. Finance Research Letters 30: 30-36. [CrossRef]

Panagiotidis, Theodore, Thanasis Stengos, and Orestis Vravosinos. 2018. On the determinants of bitcoin returns: A LASSO approach. Finance Research Letters 27: 235-40. [CrossRef]

Panagiotidis, Theodore, Thanasis Stengos, and Orestis Vravosinos. 2019. The effects of markets, uncertainty and search intensity on bitcoin returns. International Review of Financial Analysis 63: 220-42. [CrossRef]

Panagiotidis, Theodore, Thanasis Stengos, and Orestis Vravosinos. 2020. A Principal Component-Guided Sparse Regression Approach for the Determination of Bitcoin Returns. Journal of Risk and Financial Management 13: 33. [CrossRef]

Papadamou, Stephannos, Nikolaos A. Kyriazis, and Panayiotis G. Tzeremes. 2019. Unconventional monetary policy effects on output and inflation: A meta-analysis. International Review of Financial Analysis 61: 295-305. [CrossRef]

Papadamou, Stephannos, Costas Siriopoulos, and Nikolaos A. Kyriazis. 2020. A survey of empirical findings on funconventional central bank policies. Journal of Economic Studies. [CrossRef]

Patton, A. J. 2006. Modelling asymmetric exchange rate dependence. International Economic Review 47: 527-56. [CrossRef]

Phillips, P. C., S. Shi, and J. Yu. 2015. Testing for multiple bubbles: Historical episodes of exuberance and collapse in the S\&P 500. International Economic Review 56: 1043-78.

Ready, R. C. 2018. Oil prices and the stock market. Review of Finance 22: 155-76. [CrossRef]

Selgin, G. 2015. Synthetic commodity money. Journal of Financial Stability 17: 92-99. [CrossRef]

Selmi, R., W. Mensi, S. Hammoudeh, and J. Bouoiyour. 2018. Is Bitcoin a hedge, a safe haven or a diversifier for oil price movements? A comparison with gold. Energy Economics 74: 787-801. [CrossRef]

Shahzad, S. J. H., E. Bouri, D. Roubaud, and L. Kristoufek. 2019a. Safe haven, hedge and diversification for G7 stock markets: Gold versus bitcoin. Economic Modelling. [CrossRef]

Shahzad, S. J. H., E. Bouri, D. Roubaud, L. Kristoufek, and B Lucey. 2019b. Is Bitcoin a better safe-haven investment than gold and commodities? International Review of Financial Analysis 63: 322-30. [CrossRef]

Shin, Y., B. Yu, and M. Greenwood-Nimmo. 2014. Modelling asymmetric cointegration and dynamic multipliers in a nonlinear ARDL framework. In Festschrift in honor of Peter Schmidt. New York: Springer, pp. 281-314.

Sim, N., and H. Zhou. 2015. Oil prices, US stock return, and the dependence between their quantiles. Journal of Banking E Finance 55: 1-8.

Symitsi, E., and K. J. Chalvatzis. 2019. The economic value of Bitcoin: A portfolio analysis of currencies, gold, oil and stocks. Research in International Business and Finance 48: 97-110. [CrossRef] 
Tay, J. Kenneth, Joerome Friedman, and Robert Tibshirani. 2018. Principal component-guided sparse regression. arXiv.

Tibshirani, R. 1996. Regression shrinkage and selection via the lasso. Journal of the Royal Statistical Society Series B (Methodological) 58: 267-88. [CrossRef]

Torrence, C., and G. P. Compo. 1998. A practical guide to wavelet analysis. Bulletin of the American Meteorological Society 79: 61-78. [CrossRef]

Toyoshima, Y., T. Nakajima, and S. Hamori. 2013. Crude oil hedging strategy: new evidence from the data of the financial crisis. Applied Financial Economics 23: 1033-41. [CrossRef]

Tse, Y. K. 1998. The conditional heteroscedasticity of the yen-dollar exchange rate. Journal of Applied Econometrics 13: 49-55. [CrossRef]

Van der Weide, R. 2002. GO-GARCH: a multivariate generalized orthogonal GARCH model. Journal of Applied Econometrics 17: 549-64. [CrossRef]

Wei, W. C. 2018. Liquidity and market efficiency in cryptocurrencies. Economics Letters 168: 21-24. [CrossRef]

Wu, S., M. Tong, Z. Yang, and A. Derbali. 2019. Does gold or Bitcoin hedge economic policy uncertainty? Finance Research Letters 31: 171-78. [CrossRef]

(C) 2020 by the author. Licensee MDPI, Basel, Switzerland. This article is an open access article distributed under the terms and conditions of the Creative Commons Attribution (CC BY) license (http://creativecommons.org/licenses/by/4.0/). 